Teknokultura. Revista de Cultura Digital y Movimientos Sociales

ISSNe: $1549-2230$

http://dx.doi.org/10.5209/TEKN.64631

\title{
Feminist standpoint on social media sites and internet practices
}

\author{
Ana María González Ramos ${ }^{1}$
}

Recibido: 11 de junio 2019 / Aceptado: 7 de octubre 2019 Open peer reviews

\begin{abstract}
Social media sites and the internet have opened up new spaces for self-identity and the construction of social relationships. Technology communications affect human relationships by introducing innovations for individual and collective representations, but the direction and intensity of these changes may be diverse and even reinforce old patterns from the past, particularly from a gender perspective. While feminist utopians heralded the internet as a space free from gender stereotypes, evidence suggests sexist patterns still remain in place today. This work investigates several phenomena on social media sites (egobloggers, YouTubers, influencers) from a gender perspective. This analysis confirms that although some practices on social media sites display new relationships and new constructions of self-identities, others reveal the persistence of sexism and gender discrimination, even though it may be invisible to the actors and the audience. This paper argues that a code of ethics is necessary to regulate users' activity on social media sites, creating conscious values about the (un) explored consequences of common internet activities. Some guidelines for creating this code of ethics from a gender perspective are presented in the last section.
\end{abstract}

Keywords: egoblogger; ethical code; internet users; sexism; youtuber.

\section{[es] Perspectiva feminista en relación a las páginas de redes sociales y las prácticas en internet}

Resumen. Los sitios de redes sociales y de internet han abierto nuevos espacios para la auto-identidad y la construcción de las relaciones sociales. Las tecnologías de la comunicación afectan a las relaciones humanas introduciendo innovaciones para las representaciones individuales y colectivas, pero la dirección e intensidad de estos cambios posibles pueden ser diversos e incluso pueden reforzar viejas pautas del pasado, particularmente desde una perspectiva de género. Mientras la utopía feminista auspiciaba que internet sería un espacio libre de estereotipos de género, las evidencias sugieren pautas sexistas que aún permanecen en este espacio. Este trabajo investiga algunos fenómenos en las redes sociales (egobloggers, youtubers, influencers) desde una perspectiva de género. Este análisis confirma que, aunque algunas prácticas en las redes sociales muestran nuevas formas de relacionarse y nuevas construcciones de auto-identidad, otras revelan la persistencia de discriminaciones de género y sexistas, incluso aunque parecen invisibles a los actores y a la audiencia. Este trabajo establece que es necesario un código ético para regular la actividad de los usuarios de las redes sociales, creando valores conscientes sobre las consecuencias (in)explorados de las actividades habituales de internet. En la última sección se presentan algunas guías para crear este código ético desde una perspectiva de género.

Palabras clave: código ético; egoblogger; sexismo; usuarixs de internet; youtuber.

Summary. 1. Introduction. 2. Creating personal spaces across online platforms. 3. "Feminine" egobloggers versus "macho" youtubers. 4. Girls and women on the web: utopia, harassment and activism. 5. Implications and future directions. 6. References.

$1 \quad$ Universidad Autónoma de Barcelona (Spain)

E-mail: AnaMaria.González.Ramos@uab.cat 
Cómo citar: González Ramos, A. M. (2019). Feminist standpoint on social media sites and internet practices. Teknokultura. Revista de Cultura Digital y Movimientos Sociales, 16(2), 229-241.

\section{Introduction}

Social networking is flooding young people's lives, and inciting great controversy among adults, who often deride the omnipresent vision of youth glued to their screens. Adults criticize teenagers' values and practices under the lens of their own offline experiences. Consequently, they misread teenagers' compulsive obsession with cell phones and computers (Boyd, 2014). Internet practices raise challenges for the lives of both adults and young people, affecting social relationships and self-identity. Digital communication appears to be associated with innovation in the self-construction of individual and collective selves (nomadic identities, trans, boi's, grrrls, among others) that may break away from old values and social codes (Rheingold, 1993; Zoonen, 2001). However, young and old share a great number of common features, with old habits mediating social relationships through internet practices as-in the words of Turkle (2011, p. 156) these relationships contain new wine in old bottles. Technology changes human relationships by introducing innovations and new realities, although the direction and intensity of these changes may be debatable. Social media sites offer up diverse resources and outcomes that bring human relationships and self-identity into the spotlight during digital communications. The virtual space of social networking sites becomes multidimensional and remains open to transforming self-identity and relationships between people.

Therefore, the interest of this paper is twofold: first, to explore the popular communication processes materialized through the Internet from a gender perspective; second, to examine the extent to which social media sites entail a potential transformation or reproduction of gender relationships. Tradition and innovation persist on the surface of virtual relationships, thus, what kinds of changes have young people adopted? What kinds of values still remain as pieces from the past? Adults and teenagers seem to be immersed in social media, in an intertwining of old and new users, but the direction and intensity of these reproductions/ transformations are unclear.

In the following sections, I will explore some examples of internet practices that display the transformation (or maybe reproduction) of both communication and self-identity from a gender perspective. Firstly, it addresses the creation of personal spaces across online platforms. Secondly, it analyses egobloggers and YouTubers as two communities expressing themselves. Thirdly, it examines the role of women on the internet, drawing upon utopia, harassment and activism in feminist discourse. Finally, it presents a discussion and concluding remarks, with some conclusions about an ethical code on social media sites and the internet from a feminist standpoint. A textual and narrative analysis is used to address the information produced by users, the observation of users' interactions, dialogues with the audience and the interpretations of specialists.

\section{Creating personal spaces across online platforms}

Website platforms create stimulating experiences for young people, whose content receives high visibility among peers and referees (Boyd, 2014). Like in the past, young 
people need social environments where they can express themselves, private spaces in which adults are forbidden. They actually live their social roles as early adults during a liminal phase of their lives (Turner, 1967; Jenkins, 2014). Past generations gathered around "cultural tribes," characterized by a specific type of music, clothing style or occupation of space and time. In the modern age, virtual communication emerges as an immersive experience for young people (Calvert, 2002). Moreover, communication flows through multiple format types (texts, photographs, videos, emoticons, etc.), which have replaced the voice as the main way to disseminate "the message" (a self-construction of the self and its own interests). Voice calls have been replaced by different modes of communications and transmission of the information, such as instant messages, videos and photographs that express personal feelings and their own subjectivity.

Creation of online communication spaces (on both synchronous and asynchronous timelines) have created, according to Nie (2001), a paradox regarding maximum communication and minimum personal contact. However, Stern (2004) claims that virtual contacts frequently are supplemented with additional encounters in real life, eroding the illusion of the complete virtualization of contemporary lives. Also, Boyd (2014) claims that young people expand their profiles according to the expected norms in their contexts and the audience they want to attract. They choose different social media to communicate with others with regard to purposes and audience, considering previous contacts and future friendships. Unlike Turkle (1995), who asserted that online platforms offer a unique digital identity, Boyd (2014) presents young people using a plethora of profiles at the different sites where they are active online on a daily basis. From her point of view, they are multiplying their identities fluidly, creating diverse selves that are combined with physical encounters. Multiple identities add layers of different personalities and social roles for interacting with others in both physical and virtual dimensions.

Online platforms are preferred because of the increasing visibility, searchability and durability of the communication (Boyd, 2014). Messages through social media sites go beyond geographical boundaries and socio-economic-cultural groups because information technologies provide unlimited communication, creating links with people located around the globe (new and old friends). Searching for peers is easy with the support of information technology, creating close affinities among physically-distant people. Multiple interactions with heterogeneous and diverse realities open up opportunities to learn and add multi-layered dimensions to their identities and profiles on social media sites, according to many objectives, actors/ audience and contextual factors.

According to Cabiria (2008, p. 4), virtual worlds on the internet enable users to freely explore many facets of their personalities. Thus, social media sites and the internet are secure spaces to negotiate and spread sexual and gender selfrepresentations. Chen (2016) also explores sexuality through videogames, confirming that teenagers have mainly heterosexual preferences, whilst a minority explore other sexual orientations. However, most seem to use videogames while respecting family and religious rules regarding sexual norms (for example, pre-marriage sexuality). In her research, Chen explains that people play marriage videogames to safely experience sexuality, adopting technology to control their behaviours and feelings. They practice sexuality by having these experiences in virtual spaces that protect their "physical self" from moral criticism. 
Observing digital communities is stimulating in that it is sort of spying on the course of social life in contemporaneity. According to Boyd (2014, p. 5), social media has evolved from being an esoteric jumble of technologies to a set of sites and services that are at the heart of contemporary culture. Social media sites become sociological laboratories in which people experiment with themselves with other people, sharing opinions and messages in a free exploration of their personalities and diverse contexts. Subjects of these digital communications reflect the standpoint of their creators and their followers, who are protected by anonymity and a low exposure to conventional rules.

Another discussion is whether the creators adopt a fictional profile-such as a character who performs a role-or their social roles-an expression of their identity, even if it is just one of the multiple ones that they may choose to express themselves(Henderson \& Bowley, 2010). Even if they adopt a "digital self" with a fictional identity, it accomplishes one of the social roles created to interact with others. This raises a question about the continuum between virtual and real worlds harnessed by users to embed themselves in specific networks and affinities. It means that they interact with those who are able to contact them, creating a social reality beyond their physical and social context. This is important because virtual profiles also reflect the standpoint of viewers and meaning makers (Gee, 2000; Junglas et al., 2007).

Gender is one of the dimensions that produces the most contradictions and social dilemmas with information and communication technologies (ICT). International data prove that across OECD countries (Organization for Economic Co-operation and Development) the gender divide is narrowing for users of digital communications, but that the gender gap persists with regard to the number of women prosumers (ICT creators and innovators) (OECD, 2001). Nonetheless, there is a dearth of scientific that address the extent to which gender differences are important when developing social identities mediated by information technologies and whether information technologies are able to broadly transform gender schemes. Panagakos \& Horst (2006) assert that the digital inclusion of women seems to strengthen gender bias rather than change it. They are claiming the need for a previous transition in human relationships, because technology is just a tool, without a transformative capability by itself. In the following sections, this paper explores with men's and women's place in digital communities, addressing the types of postures they have taken there.

\section{3. "Feminine" egobloggers versus "macho" youtubers}

Creating social realities through digital selves in and of itself creates parallels with other socio-cultural discourses that are present in the construction of hegemonic powers in contemporary realities. Laurentis (1987) emphasizes male dominance on the "technology of gender" or the cultural practices that make the body gendered. Social media sites may reflect universal male dominance through online practices even if the prosumers are trying to innovate their self-identities and social relationships. Butler (1990) proposes the body as a mutable political entity regulated through cultural and power domains. Thus, gender performativity aims to understand marginalized identities positioned outside the stereotype of the universal gender framework, which may create new solutions to the problem of male and female stereotypes of bodies and identities. 
Gender stereotypes affect sexual and beauty practices, translating into feminine and "macho" cultures (Mosher \& Tomkins, 1988), and ICT deploys new media where people deal with these social patterns. Jeffreys (2005) claims that contemporary beauty practices related to women's bodies twist the social order to keep women subordinate to universal male dominance. Mulvey (1975) asserts that male pleasure focuses on femininity narratives, and the persistence of the female subordination/passive role. The question here is whether the technology of gender and the predominance of a patriarchal culture mould the activity of men and women on social media sites. Even if subjects are free to express themselves in digital communities, societal codes may shape gender schemes on the supposedly innovative codes of male and female users via social media sites. According to Gill (2011), the subjectivity of men and women poses no real threat to male dominance in adulthood, and young people may reproduce similar patterns on gender stereotypes. The research of Tortajada et al. (2013) confirms this realm in their findings on the qualitative analysis of Fotolog pages. They discovered that girls and boys have active roles on social networking sites, but they also concluded that teenagers have socialized gender construction, in which hypersexualization and female objectification remain.

Exploring two social communities that use different digital formats to express male and female subjectivities-egobloggers and YouTubers-this research found significant relevant gender content. At first glance, they both share the aim of attracting attention from broad audiences and the paramount presence of specific roles according to their gendered subjectivities. It was observed that men and women, as the principal makers of online contents, follow gender schemes in the production of messages and communication style. Egobloggers are associated with women and traditional feminine roles for beauty, and YouTubers with macho culture. Therefore, young people as principal actors seem to articulate a similar technology of power regarding innovative formats and contents.

Egobloggers appeared a few years ago on the internet as style webpages. Their posts on social media sites contain feminine fashion and details of the bloggers' daily life, which are made more interesting by the photographs and images posted. Some egobloggers have garnered the attention of large numbers of people around the world and some of the most famous fashion industry companies. Lovely Pepa (Alexandra Pereira), Amlul (Gala González) and Bartabac (Silvia García) are getting credit and financial gains from their posts. Fontenla (2016) carried out a quantitative analysis of international egobloggers' interactions and messages. She points out that the fashion industry has developed this advertising innovation to ensure consumption and increase loyalty. For example, the platform rewardStyle collected more than $\$ 14$ million in 2013 (more than tripling the level of July 2012) from bloggers using Instagram (Fashionista, 2013). This digital female representation illustrates the increasing attraction for young models. Girlish images are popular in the fashion industry as a result of the male gaze, a preference that influence women's choices (Mulvey, 1975; González Ramos et al., 2018). The egobloggers' expression of subjectivity alludes to this relationship between the hegemony of power and gendered technology; social structures are hierarchically distributed by male and female stereotypes and the representation of female bodies is at the centre of discourse (Kanai, 2017).

Regarding egobloggers, they are frequently female teenagers (some of them only girls) who showcase an ideal of beauty and even reflect which beauty styles should 
be the most popular. Crybaby Zine (Remi Riordan) is an 18-year-old (ages are all as of 2019) North American top blogger, who mainly posts interviews about poetry and music in her blog; "Who's that girl?" (Ophelia Horton) is the blog of an English 15 -year-old who writes an adolescent diary; Evita Nuh is a 14-year-old Indonesian blogger, also a young creative entrepreneur and a freelance editor. Crybaby Zine expresses her teenage feelings; Ophelia Horton represents an ordinary profile; and Evita Noh is an independent girl.

All of these girls showcase the idea of freedom and independence from adult protection, and the fact that they are teenagers underlines their ability to become celebrities. It creates the illusion of gaining power over viewers across the globe, reinforced by neoliberalist practices that lead the protagonists' role of these teenagers (sometime, only children) becoming fashion industry professionals. Egoblogger phenomena make many girls' aspirations a reality, they believe they can become famous with the internet, as some of these cases demonstrate. In addition, the female body becomes central for social media sites (Kanai, 2017). Following Gill (2011) statements, egobloggers do not pose a real threat to male dominance. The creativity and independence shown by these girls remains strongly intertwined to the physical appearance of women and the "feminine sex". Tortajada et al. (2013) find that young people reproduce gender identities by insisting on male and female traditional stereotypes. Therefore, the message of these blogs does not entail a real threat to male dominance, but instead confirms the desire of the androcentric adult gaze and the patriarchal structure.

The profile of YouTubers reveals several differences with egobloggers, although both share an interest in their search for popularity and celebrity. Increasing viewers is also the purpose of YouTubers who post a great variety of themes according to their aim to attract the maximum number of viewers. They sing, create learning courses, criticize movies and music, do hilarious performances and play games, to name just a few of the large list of activities. Any theme is possible on their social media sites if it creates a trending topic. YouTube is considered an example of "cocreative" and participative culture that leads to entrepreneurship and success (Burgess \& Green, 2012). As egobloggers, they get viewers that support personal messages as role models and influencers and, therefore, they earn money with their online practices. In the end, egobloggers and YouTubers have financial aims intertwined with popularity as common goals.

A typical YouTuber used to be a young white teenager. YouTuber culture is clearly androcentric in both content development and communication style. Unlike egobloggers, YouTubers rarely showcase handsome physical appearances and the style of their messages is generally recorded in a low quality: the YouTuber is placed in the foreground, the background of the shot is poor and motion is underdeveloped. The carefully-posed photographs and style of egobloggers contrasts with the neglected appearance of YouTubers. Emotions and expressive communication create the atmosphere of the videos by male YouTubers; maybe the image takes up the whole screen or the YouTuber is even completely invisible, only represented by his (or her in a minority of cases) "male" voice (such as the tutorials and training courses created by YouTubers). The body is not important, as it stems from the heterosexual and androcentric codes of Western culture (Laurentis, 1987; Grosz, 1994). This means that even the absence of body representation matters in the technology of gender. 
YouTuber channels showcase innovative formats and the mediation of technologies to spread messages all over the world. A multiplicity of contents and motivations inspires YouTubers, from the most serious videos (e.g. training courses) to foolish ones (e.g. nonsensical comments). This analysis is particularly interested in YouTubers who make bizarre videos regarding killer clowns (Mateo Moroni), teasing jokes (Rémi Gaillard), dangerous skateboarding (Vitaly Zdorevetskiy) and men in their rooms talking about a wide range of themes aimed at attracting the attention of thousands of viewers. YouTubers record short conversations with colourful images and fast camera movements. In this context, macho culture is both a way to attract attention and to demonstrate the persistence of implicit codes that are widespread among young people. YouTubers frequently use "bitch" and "abusers" when referring to girls and women. In Spain, many of these YouTubers have been widely denounced by feminists, for example, Dalas Review, Jorge Cremades, Álvaro Reyes, Wismichu, El Rubius and Auroplay. However, their popularity assures their impunity, as well as reinforcing the macho culture, normalizing gender stereotypes and encourages neglecting strict measures against gender violence and offensive language.

In summary, young people use social media sites intensively with diverse purposes to express themselves, demonstrate freedom, and pursue success, seeking popularity and the spreading of their messages (number of viewers, sponsors, etc.). While these two communities' goals may seem equal, the styles of expression are different for gendered cultural practices based on traditional roles about what male and female constructions are. The comparison between egobloggers and YouTubers shows the reproduction of gender stereotypes, with content and communication styles associated with the technology of gender: the female body at the centre of the egobloggers' discourse and the reinforcement of rude behaviour of many YouTubers. Therefore, patriarchy persists in shaping the social codes of men and women (Jeffreys, 2005; Gill, 2003) by creating role models for young people in the new media.

\section{Girls and women on the web: utopia, harassment and activism}

The "WP: Clubhouse report" (Lam et al., 2011) points out that the gender gap on the internet has shrunk, although there is still a low percentage of gender content on websites and the "resistance culture" against women prevails, for example, as professional gamers or developers. Likewise, the International Game Developers Association (IGDA, 2015) finds that women 18 and younger represent $33 \%$ of the game-playing population, which is more than men younger than $18(15 \%)$. The same study also revealed that $75 \%$ of the workforce in this sector is male. This evidence reveals how paradoxical the idea is of a feminist utopia on the internet causing gender equality through the materialization of horizontal relationships and unbiased patterns on gender issues (Zoonen, 2001; Gill, 2011). The idea is that the abolition of gender inequalities follows from the absence of previous hierarchy and power regimes (Penny, 2014), although the structure of power persisted at the onset of the internet, just like in cultural patterns in contemporary society. As I shown in this section, the vulnerability of girls and women on the internet is a result of the reinforcement of traditional types of discrimination, related to unfriendly environments and stereotyped images of men and women flooding cyberspaces, and the subordination of all of society to the male gaze. 
The first impediment is related to workplaces, where the scant representation of women in ICT areas evidences discrimination and prejudices at work (Cohoon \& Aspray, 2006; Castaño, 2008; González Ramos et al., 2017). This problem has been widely addressed and exceeds the scope of this work. The second impediment concerns the production of innovation and technologies that are embedded in male culture and that hinder the female perspective (Haraway, 1988; Lie \& Sørensen, 1996), which claims all women are technophobic. The third point refers to "political language" (Leung, 2011) and the many manifestations of discrimination through the verbal violence related to gender. For example, female ICT workers usually use nicknames that hide or prevent stereotypes against women based on their experience in this workplace. Sexist language is systematically used by male workers who, for example, call their colleagues "brothers" or "guys" or use the "neutral" (male) adjectives that implicitly ignore sex differences. In their research, Toombs et al. (2015) have found that hackers are blind to gender, race and social class differences, taking universal male dominance for granted. Moreover, women working in this area claim that gender stereotyped language is used among ICT professionals. They affirm that women are usually attributed as dumb and incompetent ("it's so easy that my mom can do it") and hypersexualized expressions such as "hot algorithm". The study of Terrell et al. (2016) shows that disclosing a female identity led to more rejection and sexist behaviours than when gender identity was unknown. This evidence reflects the subordination of the female role in ICT environments, as well as in socio-cultural environments. Leung (2011, p. 93) also expressed that women swear on the internet because of the anonymity of the virtual world and an accumulation of emotional language. These patterns produced by adults may extend to young people's behaviours, reproducing sexism and verbal violence of both men and women alike.

Anonymity on the internet plays a double role as a means of freedom of expression and clear protection when committing offenses. Creating a culture of respect in cyberspace is necessary for regulating violence and social discrimination (Keith \& Martin, 2005; Adam, 2005). The victims of verbal offense and privacy invasion on social media also leads to solitude and vulnerability. For some of them what happens on social media sites is more real than their daily experiences (Turkle, 1995). Verbal abuse on social media sites echoes other dimensions of childhood and modifies children's behaviour. Cyberbullying reproduces the processes of physical abuses on the playground (Hinduja \& Patchin, 2010; Ringrose \& Eriksson, 2011). Body and physical appearance are the focus of a great number of offenses, and it is precisely the factor of one the most critical phases of adolescence: changes in the body, identity acceptance and discovery of sexuality. According to Child Helpline International (2012), 73\% of girls and 27\% of boys have been victims of sexual abuses through the internet.

Zoe Quinn is a game developer who suffers online harassment because of her work. She was attacked through "\#gamergate" because she created games with a feminist slant. Two of her most popular videogames are Depressed Quest and Help List designed to understand mental illness and to create female networks, respectively. Even if these games are not explicitly designed for women or related to a feminist political stand, Zoe Quinn was criticized because of the construction of games based on non-violence and female culture. Sexism in playing games is surely related to the high representation of male developers and mistaken ideas about who the players are. Although \#gamergate's declaration (Clercq, 2016) points out a different explanation, as being "overly feminist and alienating traditional gaming". Other female 
celebrities also report high risks of receiving emotional harm, threats to their rights to privacy, sexual invasion and defamation (Keats, 2016). Sexuality and female bodies focus the attention of people in both real contexts and virtual communities.

However, there are also good examples on the internet of breaking codes and facing cyber-harassment and social abuses (videos, online recommendations and apps). Social media sites are used by social movements for human rights (e.g. \#Metoo, \#BringBackOurGirls), LGBTI movements (e.g. http://q42.org.uk/faith/) and feminists (e.g. https://feministkilljoys.com) who develop helpful information and resources. Digital communities provide visibility and spreadability of private messages (Routledge, 2003; Boyd, 2014), organize people around meaningful movements and promote actions for vulnerable groups. According to Friedman (2002), the internet fosters democratic relations and designs effective strategies for the mobilization of civil society. She considers the internet a critical resource for gender equality, supporting marginalized subjects dealing with ostracized ideas and identities. Although Fenton (2008) warns that multiplication of resources leads to the fragmentation of forces for grassroots movements, and the multiplication of messages (albeit contradictory at times) may confuse the audience.

Fluidity of identities is surely a novelty dimension of the internet which exports transferable model across the globe (Rheingold, 1993; Nijsten, 2016). An example of this spreadability of identities is the hikikomori culture (meaning "social withdrawal"); young people who refuses to leave their houses, and isolate themselves from society, remaining in their homes. This community, characteristic of Japan, have garnered great attention worldwide, with thousands of cases reported. Many people over the world are copying this model from youth Japanese culture, like this was their own culture of reference. Unlike homogeneity, manifold subjectivities rise up, adopting multiple forms. Ormrod (1985: 39) claims that the illusion of fixity and fluidity in young people's subjectivity supports both the persistence and diversion of social codes. This idea is linked to the assertion of Boyd (2014) about the creation of different layers of identity through our social media sites, and the doing and undoing of identity across contexts (Butler, 1990). It enhances the creation of a fluid and transformative self-identity.

To summarize, the internet reflects heteronormativity, androcentrism and male culture, since it is an instrument for people who follow conventional values in a global society. On the one hand, the utopia of horizontal relationships, sexual freedom and zero gender discrimination have failed in general terms. On the other hand, the multiplicity of messages and formats, developing digital communities, points to a diversification of identities and grassroots movements to defend minority groups. Digital platforms are also potential tools for creating a fluid and transformative reconceptualization of self-identities. However, this is a simple tool that may pave the way for change, but gender roles embed the discourse of male and female prosumers. Although social media sites may favour diverse social roles, men and women mainly redo social codes.

\section{Implications and future directions}

Many expressions of young people on social networking sites are copying adult behaviours and, consequently are embedded in patriarchal values, narrowing their expressions of identity. YouTubers and egobloggers appear creating a social space of influence while 
they adopt a professional and lucrative function. Despite young people's standards seem to oppose adult' ones, both are nonetheless contaminated by gender stereotypes, due to male culture invading every dimension of the social sphere. Liberalism carves out a utopia of equalitarian, horizontal and non-profit goals that enlivened the pioneer internet participants. New and old patterns coexist on social media sites in the construction of self-identity and the creation of the spread ability of messages to other people.

Adults' supervision of young people's behaviour is necessary, as well as the training of both (youth and adults) to exercise their freedom while responsibly using the internet and social media sites. Information technology offers visibility to personal and collective messages, experimenting with alternative conducts, including sexuality. The novelty in youth's relationships is that they are mediated by online platforms consisting of displaying more than one identity, according to their preferences and contexts that they try to control through anonymity. Paradoxically, anonymity provokes both opportunities and risks, evenly intertwined in the materiality of virtual relationships. Social media sites are a powerful tool to generate diverse sides of identities and subjectivity, highly transmissible and fluid trends; this is the time to change traditional patterns into gender mainstreaming and transform vulnerability into equal opportunities. Male culture embedded in social platforms blocks women from being added to creation processes and preserves sexist attitudes and female discrimination. A future direction will address how to materialize this ethical code via culture and social media sites, because the transformation of internet practices should be constructed both at real and virtual spaces.

The feminist ethical code on social networks pleads halt sexism and discriminative practices. The code should testify how anonymity benefices unethical conducts, confronting them and making the anonymity only will be at service of freedom of expression and the protection of the vulnerable people. Social media sites should provide an ability for self-expression to reinvent empowering selves and bridges toward self-esteem. A place where, instead of reproducing femininity and masculinity under androcentric systems, produces multiplicity and opportunities to share knowledge and equal labour conditions through horizontal frameworks for both women and men. Information technologies as data providers that -instead of profiting from personal profiles- offer people the possibility of adapting a huge amount of information into formats that we human subjects are able to deal with.

Although this code of ethics might seem as utopian as the first cyberfeminists had imagined (like the one proposed by Sadie Plant), it is as real as any other political strategy that we can adopt. As I have shown in the article, information technology is not damaging in itself, but part of an entangled quantum of human and non-human practices at particular socio-cultural times. It is a matter of habits; exploring and analysing how these habits evolve might also offer solutions regarding how to promote changes in both physical and virtual environments.

\section{References}

Adam, A. (2005). Gender, Ethics and Information Technology. Gordonsville, Palgrave MacMillan.

Boyd, D. (2014). It's Complicated: The Social Lives of Networked Teens. New Haven: Yale University Press. 
Burgess, J. E. and Green, J. B. (2012). YouTube: Online Video and Participatory Culture. Polity Press.

Butler, J. (1990). Gender trouble. New York: Routledge.

Cabiria, J. (2008). Virtual World and Real World Permeability: Transference of Positive Benefits for Marginalized Gay and Lesbian Populations. Journal of Virtual Worlds Research, 1(1), https://journals.tdl.org/jvwr/index.php/jvwr/article/view/284. Accessed January 072018.

Calvert, S. L. (2002). Identity construction on the internet. In Sandra L. Calvert, Amy B. Jordan \& Rodney R. Cocking, Children in the Digital Age: Influences of Electronic Media on Development (pp. 57-70). Westport, CT: Praeger.

Castaño, C. (ed.) (2008). La segunda brecha digital. Madrid: Ediciones Cátedra.

Chen, Ch-P. (2016). Playing with digital gender identity and cultural value. Gender, Place \& Culture, 23 (4), 521-536, https://doi.org/10.1080/0966369X.2015.1013455

Child Helpline International (2012). Bullying: Analysis of 10 year Global Data. Briefing Paper on Bullying. Accessed February 10, 2017, http://www.childhelplineinternational. org/media/57468/chi_briefing_paper_bullying.pdf

Clercq, L. de (2016). Why Are So Few Women Developing Video Games. UniteIT e-Inclusion Network. Accessed February 10, 2017,

http://www.unite-it.eu/profiles/blogs/why-are-so-few-women-developing-video-games

Cohoon, J.M. and Aspray, W. (eds.) (2006). Women and Information Technology: Research on Under-Representation. Massachusetts: MIT Press.

Fashionista (2013). How Personal Style Bloggers Are Raking in Millions. Fashionista. Accessed February 10, 2017, http://fashionista.com/2013/08/how-personal-stylebloggers-are-raking-in-millions\#1

Fenton, N. (2008). Mediating solidarity. Global Media and Communication, 4 (1), 37-57, https://doi.org/10.1177/1742766507086852

Fontenla, J. (2016). Online Communication and Galician Top Bloggers. Media and Metamedia Management, 503, 383-390, https://doi.org/10.1007/978-3-319-46068-0_50

Friedman, E. J. (2015). The Reality of Virtual Reality: The Internet and Gender Equality Advocacy in Latin America. Latin American Politics and Society, 47, 1-34, https://doi. $\operatorname{org} / 10.1111 / \mathrm{j} .1548-2456.2005 . t b 00317 . x$

Gee, J. P. (2002). Identity as an analytic lens for research in education. Review of Research in Education, 25, 99-125, https://doi.org/10.3102/0091732X025001099

Gill, R. (2003). From sexual objectification to sexual subjectification: the resexualisation of women's bodies in the media. Feminist Media Studies, 3 (1), 100-106, https://doi. org/10.1080/1468077032000080158

- (2011). Sexism reloaded, or, it's time to get angry again! Feminist Media Studies, 11 (1), 61-71, https://doi.org/10.1080/14680777.2011.537029

González Ramos, A. M., Vergés Bosch, N. and Martínez García, J.S. (2017). Las mujeres en el mercado de trabajo de las tecnologías. Revista Española de Investigación Sociológica, 159, 73-90, http://dx.doi.org/10.5477/cis/reis.159.73

González Ramos, A. M., Enguix, B. and Revelles-Benavente, B. (2018). Who possesses "possessed women" Women and Female Bodies as Territories for Male Interference? Revista Latinoamericana de Estudios sobre Cuerpos, Emociones y Sociedad, 27 (10), 85-94.

Grosz, E.A. (1994). Volatile Bodies: Toward a Corporeal Feminism. Bloomington: Indiana University Press.

Haraway, D. (1988). Situated Knowledges: The Science Question in Feminism and the Privilege of Partial Perspective. Feminist Studies, 14 (3), 575-599, http://dx.doi. org $/ 10.2307 / 3178066$ 
Henderson, Alison \& Bowley, Rachel (2010). Authentic dialogue? The role of 'friendship' in a social media recruitment campaign. Journal of Communication Management, 14 (3), 237-257, http://dx.doi.org/10.1108/13632541011064517

Hinduja, S. and W. Patchin, J. (2010). Bullying, Cyberbullying, and Suicide. Archives of Suicide Research, 14 (3), 206-221, http://dx.doi.org/10.1080/13811118.2010.494133

IGDA (2015). Developer Satisfaction Survey 2015 Summary Report. DSS Industry Trends \& Future Outlook Report. Accessed February 10, 2017 https://goo.gl/kHwIOE.

Jeffreys, S. (2005). Beauty and Misogyny: Harmful Cultural Practices in the West. London: Routledge.

Jenkins, R. (2014). Social Identity. London \& New York: Routledge.

Junglas, I.A., Johnson, N., Steel, D., Cham, A. and Mac Loughlin, P. (2007). Identity Formation, Learning Styles and Trust in Virtual Worlds. Data Base for Advances in Information Systems, 38 (4), 90-96, https://doi.org/10.1145/1314234.1314251

Kanai, A. (2017). The best friend, the boyfriend, other girls, hot guys, and creeps: the relational production of self on Tumblr. Feminist Media Studies, 17 (6), 911-925, https:// doi.org/10.1080/14680777.2017.1298647

Keats Citron, D. (2014). Hate Crimes in Cyberspace. Harvard: Harvard University.

Keith, S. and Martin, M. (2005). Cyber-Bullying: Creating a Culture of Respect in a Cyber World. Reclaiming Children and Youth, 13 (4), 224-228, https://doi.org/10.1016/j. paid.2006.03.008

Lam, Sh. (Tony) K., Uduwage, A., Dong, Zh., Sen, Sh., Musicant, D.R., Terveen, L. and Riedl, J. (2011). WP:Clubhouse? An Exploration of Wikipedia's Gender Imbalance. Proceedings of the 7th International Symposium on Wikis and Open Collaboration, 1-10. Accessed January 7, 2018 http://files.grouplens.org/papers/wp-gender-wikisym 2011.pdf

Laurentis, T. de (1987). Technologies of Gender: Essays on Theory, Film, and Fiction. Indiana: Indiana University Press.

Leung, L.Y. M. (2011). Pro-suming" Swearing (Verbal Violence) "Affect" as feminist (Internet) criticism. Feminist Media Studies, 11 (1), 89-94, https://doi.org/10.1080/146 80777.2011.537036

Lie, M. and Sørensen, K. H. (1996). Making Technology Our Own?: Domesticating Technology Into Everyday Life. Scandinavian University Press North America.

Mosher, D.L. and Tomkins, S.S. (1987). Scripting the macho man: Hypermasculine socialization and enculturation. The Journal of Sex Research, 25 (1), 60-84, https://doi. org/10.1080/00224498809551445

Mulvey, L. (1975). Visual Pleasure and Narrative Cinema. Screen, 16 (3), 6-18, https://doi. org/10.1093/screen/16.3.6

Nie, N. H. (2001). Sociability, Interpersonal Relations, and the Internet. Reconciling Conflicting Findings. American Behavioral Scientist, 45 (3), 420-435, https://doi. org/10.1177/00027640121957277

Nijsten, C. (2016). Fluid Identity and Cultural Sensitivity in Youth. Brock University. Accessed January 7, 2018, http://hdl.handle.net/10464/10400

OECD (2001). Understanding the Digital Divide. Paris: OECD.

Panagakos, A. and Horst, H. A. (2006). Return to Cyberia: technology and the social worlds of transnational migrants. Global Networks, 6 (2), 109-124, https://doi.org/10.1111/ j.1471-0374.2006.00136.x

Penny, L. (2014). Unspeakable Things: Sex, Lies and Revolution. London: Bloomsbury Publishing. 
Plant, S. (1995). Zeros and Ones, Digital Women and the New Technoculture. New York: Doubleday.

Rheingold, H. (1993). The Virtual Community. New York. HarperPerennial. Ringrose, J. and Eriksson, K. (2011). Gendered risks and opportunities? Exploring teen girls' digital sexual identity in postfeminist media contexts. International Journal of Media and Cultural Politics, 7 (2), 121-138, http://dx.doi.org/0.1386/macp.7.2.121_1

Routledge, P. (2003). Convergence space: process geographies of grassroots globalization networks. Transactions of the Institute of British Geographers, 28, 333-349, https://doi. org/10.1111/1475-5661.00096

Stern, S. R. (2004). Expressions of Identity Online: Prominent Features and Gender Differences in Adolescents' World Wide Web Home Pages. Journal of Broadcasting \& Electronic Media, 48 (2), 218-243, http://dx.doi.org/10.1207/s15506878jobem4802_4

Terrell, J., Kofink, A., Middleton, J., Rainear, C., Murphy-Hill, E. and Sallings, J. (2016). Gender Bias in Open Source: Pull Request Acceptance of Women Versus Men. PeerJ PrePrints, 3:e111, https://doi.org/10.7717/peerj-cs.111

Toombs, A., Bardzell, Sh. and Bardzell, J.(2015). The Proper Care and Feeding of Hackerspaces: Care Ethics and Cultures of Making. Proceedings of the HCI Conference. Accessed February 10, 2018

https://www.researchgate.net/publication/275213865_The_Proper_Care_and_Feeding_of_ Hackerspaces_Care_Ethics_and_Cultures_of_Making

Tortajada, I., Araüna, N. \& Martínez, I. (2013). Advertising Stereotypes and Gender Representation in Social Networking Sites. Comunicar, 41 (XXI), 177-186, http://dx.doi. org/10.3916/C41-2013-17

Turkle, Sh. (2015). Life on the Screen: Identity in the Age of the Internet. New York: Touchstone.

- (2011). Alone Together: Why We Expect More from Technology and Less from Each Other. New York: Basic Books.

Turner, V. (1967). Betwixt and Between: The Liminal Period in Rites of Passage. The Forest of Symbols, 46-55. Ithaca, NY: Cornell University Press.

Zoonen, L. van (2001). Feminist Internet Studies. Feminist Media Studies, 1 (1), 67-72, http://dx.doi.org/10.1080/14680770120042864 